\title{
A job interview in the MRI scanner: How does indirectness affect addressees and overhearers?
}

\author{
Jana Bašnákováa ${ }^{\mathrm{a}, \mathrm{b}, *}$, Jos van Berkum ${ }^{\mathrm{d}}$, Kirsten Weber ${ }^{\mathrm{a}, \mathrm{e}}$, Peter Hagoort ${ }^{\mathrm{a}, \mathrm{c}}$ \\ ${ }^{a}$ Max Planck Institute for Psycholinguistics, Nijmegen, Netherlands \\ ${ }^{\mathrm{b}}$ Institute of Experimental Psychology, SAS, Slovakia \\ ${ }^{\mathrm{C}}$ Donders Institute for Brain, Cognition and Behaviour, Radboud University Nijmegen, Netherlands \\ d UiL-OTS, Department of Languages, Literature and Communication, Utrecht University, Netherlands \\ e Harvard Medical School, Boston, USA
}

\section{A R T I C L E I N F O}

\section{Article history:}

Received 1 October 2014

Received in revised form

26 March 2015

Accepted 27 March 2015

Available online 6 April 2015

\section{Keywords:}

Indirect meaning

Addressees

fMRI

ToM

Affective processing

Discourse

Face-work

\begin{abstract}
A B S T R A C T
In using language, people not only exchange information, but also navigate their social world - for example, they can express themselves indirectly to avoid losing face. In this functional magnetic resonance imaging study, we investigated the neural correlates of interpreting face-saving indirect replies, in a situation where participants only overheard the replies as part of a conversation between two other people, as well as in a situation where the participants were directly addressed themselves. We created a fictional job interview context where indirect replies serve as a natural communicative strategy to attenuate one's shortcomings, and asked fMRI participants to either pose scripted questions and receive answers from three putative job candidates (addressee condition) or to listen to someone else interview the same candidates (overhearer condition). In both cases, the need to evaluate the candidate ensured that participants had an active interest in comprehending the replies. Relative to direct replies, facesaving indirect replies increased activation in medial prefrontal cortex, bilateral temporo-parietal junction (TPJ), bilateral inferior frontal gyrus and bilateral middle temporal gyrus, in active overhearers and active addressees alike, with similar effect size, and comparable to findings obtained in an earlier passive listening study (Bašnáková et al., 2014). In contrast, indirectness effects in bilateral anterior insula and pregenual ACC, two regions implicated in emotional salience and empathy, were reliably stronger in addressees than in active overhearers. Our findings indicate that understanding face-saving indirect language requires additional cognitive perspective-taking and other discourse-relevant cognitive processing, to a comparable extent in active overhearers and addressees. Furthermore, they indicate that face-saving indirect language draws upon affective systems more in addressees than in overhearers, presumably because the addressee is the one being managed by a face-saving reply. In all, face-saving indirectness provides a window on the cognitive as well as affect-related neural systems involved in human communication.
\end{abstract}

(c) 2015 Elsevier Ltd. All rights reserved.

\section{Introduction}

Language is a powerful discrete combinatorial coding system, a verbal sign system that allows people to communicate very precisely about a potentially infinite amount of things. However, that does not mean that language comprehension is just a straightforward "code cracking" process, where word meaning is combined according to the rules of grammar. Pragmatic analyses (Clark, 1996; Grice, 1975; Levinson, 2006; Tomasello, 2008) have

\footnotetext{
* Correspondence to: Max Planck Institute for Psycholinguistics, Wundtlaan 1, 6525 XD Nijmegen, The Netherlands.

E-mail address: jana.basnakova@mpi.nl (J. Bašnáková).
}

made it very clear that language comprehension always involves a range of inferential processes whereby the linguistic signs are 'contextualized', i.e., interpreted in terms of their specific context, and, above all, the likely intentions of the current speaker. Inferences about what the speaker might mean are needed at various levels of the comprehension process. We need to think about the speaker to resolve reference, in order to work out what expressions such as "I", "today", or "this paper" refer to in a particular utterance, and along the way fixate the relevant meaning of "paper". We also need it to work out things that, although not explicitly said, are conversationally implicated by the speaker in a given situation, such as when "there's a garage around the corner" is meant to also convey "and it's open now, so you can get some gas there" (Clark, 1996). 
Although lagging substantially behind cognitive neuroscience research on the code-cracking aspects of language use, research on the neural substrate of this inferential side of language comprehension is now picking up speed (e.g., see Bambini and Bara, 2012; Hagoort and Levinson, 2014; Hoeks and Brouwer, 2014; Van Berkum, 2009, 2010 for reviews). One useful research strategy is to study communicative inference in situations where language itself cannot be used (e.g., Noordzij et al., 2009; Stolk et al., 2013), or where the language used is referentially ambiguous (e.g., Nieuwland and Van Berkum, 2008; Van Berkum et al., 1999). Another fruitful approach is to study the comprehension of verbal utterances in contexts where the ultimate intended speaker meaning is very different from what is explicitly said, such as when speakers use irony (Spotorno et al., 2012), or when they are indirect (e.g., Bašnáková et al., 2014; Jang et al., 2013; Van Ackeren et al., 2012). Frequent activations in areas associated with 'mentalizing' or theory-of-mind (ToM) in these studies corroborate the idea that language comprehension will also typically require inferences about the speaker's perspective and intentions.

Indirectness in language is particularly interesting, because apart from providing a window on the inferential, cognitive perspective-taking aspects of language comprehension (what is the speaker really saying?), it also provides a window on the social and therefore more affective aspects of language use. Indirectness allows us to negotiate our social identities (Holtgraves, 2002), to interact with each other more strategically, or tactfully, than we would otherwise be able to (Lee and Pinker, 2010; Pinker et al., 2008). When used judiciously, indirectness can help us get what we want without running the risk of losing face ("Care for a last drink at my place?") or of ending up in jail ("Nice store you got there, would be a shame if something happened to it"). Related, and foregrounded in research on politeness (e.g., Brown and Levinson, 1987; Goffman, 1959), indirectness can be used to make sure that others don't lose face ("Your draft paper does have room for improvement"). Because all of this, linguistic indirectness is an ideal domain within which to explore the interactive, inherently interpersonal and affective machinery that underlies our everyday use of language (Van Berkum, 2015; Levinson, 2006).

In a recent fMRI study (Bašnáková et al., 2014), we examined the neural substrate of interpreting indirectness by having listeners overhear indirect utterances that involved such face-saving social navigation. An fMRI participant would, for example, hear a conversation between two friends in which one just gave a talk and asked the other whether he liked it, upon which the reply was a friendly pronounced "It is hard to give a good presentation". Compared to overhearing the same utterance in a condition where it served as a much more direct reply ("How is it to give a good presentation?"), such face-saving indirect replies increased activity in three important sets of brain regions. First, as predicted from pragmatic analyses of speaker meaning interpretation, working out the implicit meaning, or 'conversational implicature' (Grice, 1975), of indirect replies increased activity in core regions of the ToM network involved in cognitive perspective-taking: medial prefrontal cortex and right temporo-parietal junction (TPJ). Second, face-saving indirectness increased activation in mainly righthemisphere temporal and frontal regions that have also been implicated in discourse-level language processing, possibly reflecting the increased inferential complexity, situation modeling and/or working memory demands associated with more complex discourse. And third, consistent with the above analysis of the social utility of indirectness, face-saving indirect replies also elicited stronger activation in insular and anterior cingulate cortex (ACC), potential signs of more affective perspective-taking (e.g., empathy), or of some other affective stance (e.g., sympathy, respect, disapproval) towards the speaker or his/her addressee. The aim of the current study is to replicate these fMRI findings, and to extend them to importantly different, more dynamic arenas of language use.

In everyday conversations, utterances are typically designed for particular addressees and relevant to their lives. In the vast majority of cognitive neuroscience studies on language, however, participants are presented with utterances that are completely irrelevant to their own concerns, and usually also not really addressed to them. This was also the case in our previous study, where indirect replies were embedded in dialogs by other people and about other people; dialogs which the participant was simply overhearing as an impartial listener. Even though this might not be a cause for concern in examining low-level syntactic or singleword processing, for research on the neural correlates of pragmatic interpretation, it is important to establish to what extent the findings obtained with such passive overhearing generalize to more typical communicative situations where language is more directly relevant to the listener. In real-life encounters, relevance might be achieved in several ways: either because information conveyed by an utterance informs the listener's next action (language as action rather than product; Clark, 2006), or because the listener him- or herself is directly addressed by the speaker (see Schober and Clark, 1989). Such distinctions seem to be particularly important for face-saving utterances that involve interpersonal, social navigation.

In the current fMRI study, therefore, we explore whether the neural systems that increased their activity in response to passively overheard face-saving indirectness (Bašnáková et al., 2014) show a similar increase in two more engaging situations: one where the face-saving indirect utterances are more actively overheard by the fMRI participant because the information is needed for a later decision (active overhearer condition), and one where when the indirect utterances are not only decision-relevant but also addressed to the fMRI participant him- or herself (active addressee condition). If our previous indirectness effects generalize to these two other arenas of language use, this would be good news for research with more passive language comprehension paradigms. However, it is not at all inconceivable that in such more engaging linguistic interactions, the use of face-saving indirect replies elicits partly different indirectness effects. We formulate more specific predictions after explaining the experimental paradigm.

\subsection{The Job Interview paradigm}

We created an experimental setting that provided a maximally natural context for face-saving indirect replies - a mock job interview. In a job interview, applicants can and will often use indirectness as an efficient strategy to make the best possible impression, for example attenuate the effect of potential 'shortcomings', such as not having particular experience or skill. After all, it is usually more strategic to reply to a question about whether you have some vital qualification for the job with, say, an indirect "I'm planning to take a course this summer" than with a direct "no, I don't have that skill". In the study, each fMRI participant received various job ads, together with a list of designated questions to be asked about the applicant's skills, background and experience. In the active addressee condition, the participant acted as an interviewer who posed the predefined questions to three "job candidates", and, critically, who therefore also was the addressee for each reply. In the active overhearer condition, the participant overheard another interviewer posing the same questions to these job candidates, and therefore also overheard each of the critical replies given to that interviewer. In both conditions, the task of the fMRI participant was to evaluate each candidate in order to choose the best one for the job. Thus, even when overhearing an interview conducted by somebody else, the participant should still be interested in going 'beyond the language given', and interpret the 
candidate's replies up to the deepest possible level.

As in our previous study, the main comparison was between processing of the indirect replies and that of the direct replies, the latter serving as a baseline, for example,

(1a) Q: "Are you fluent in any foreign languages?" $\mathrm{R}$ : "I am planning to take a language course this summer" (indirect reply)

(1b) Q: "What are your plans after graduation?" $\mathrm{R}$ : "I am planning to take a language course this summer" (direct reply)

Importantly, the directness or indirectness of a reply was solely determined by the nature of the question that preceded it in the interview, so that the critical replies were identical at the word and sentence level, and any differences in activation would thus reflect the processing consequences of indirectness itself. In addition, in order to maintain tight experimental control over relevant psycholinguistic variables, the candidates' replies in both active addressee and active overhearer conditions were pre-recorded and played back to the participants (see Hoeks, Schoot, Neijmeijer, and Brouwer, in preparation, for a comparable approach).

What do we predict for the differential effects of indirectness in active overhearers and active addressees? First, note that the study is not designed to test for general 'main effects' of overhearing vs. being addressed. Our key interest is in the neural substrate of inferential processing as well as the associated socio-affective processes in language comprehension, which we aim to make visible by comparing the response to face-saving indirect replies with that to baseline direct replies. Specifically, the aim is to see whether prior differential indirectness effects obtained in passive overhearers (Bašnáková et al., 2014) generalize to active overhearers, and whether findings obtained with active overhearers generalize to active addressees. It is critical to keep this differential logic in mind, and to realize that in this logic - as in any subtraction logic - the absence of an indirectness effect in some region of interest does not mean that this region is not engaged by both direct and indirect replies. After all, although presumably to a smaller degree than indirect ones, even our direct replies should require some inferencing in order to arrive at the speaker's intended meaning (Grice, 1975). And in our paradigm, also these utterances are part of a situation that requires the understanding and evaluation of the speaker's social moves, qualifications, and character.

For each of the two active participant roles (overhearer, addressee), we organize our predictions in terms of the three sets of processes foregrounded by face-saving indirectness in our earlier passive overhearer study (Bašnáková et al., 2014): cognitive perspective-taking, other cognitive processes required to handle complex discourse, and affective processing. We also exploit a pragmatics distinction that is highly relevant for thinking about face-saving indirect replies: the distinction between the speaker's referential and social intentions (Tomasello, 2008). Referential intentions involve what a speaker wishes to draw attention to, and what listeners typically analyze in terms of "what is being talked about", i.e., a situation model (Zwaan and Radvansky, 1998). Social intentions involve what a speaker wishes to achieve, by talking about that something, at the level of social actions (Tomasello, 2008): what is it that the speaker ultimately wants a listener to do, know, or feel?

\footnotetext{
${ }^{1}$ More examples of direct and indirect question-reply pairs can be found in Table 2.
}

\subsection{Predictions for active overhearers}

\subsubsection{Cognitive perspective-taking}

Just like passive overhearers, indirectness should lead active overhearers to engage in additional cognitive perspective-taking relative to direct replies, e.g., to work out that in reply to the fluency question in (1a), the utterance "I am planning to take a language course this summer" is also implicitly conveying "no, I am not fluent yet". We therefore expect core nodes of the mentalizing network to show up, at least those observed in our earlier study ( $\mathrm{mPFC}$ and TPJ), and possibly also other ones (such as the precuneus, e.g., Schurz et al., 2013; Van Overwalle and Baetens, 2009; Mar, 2011). Whether the size or extent of the indirectness effect in this network will be larger or smaller than for passive overhearers is difficult to predict. In the job interview setting, the indirect reply may well induce additional cognitive perspective-taking to construe currently important aspects of the speaker's social intention, e.g., that this candidate prefers to downplay absent qualifications, and may even want to fool the interviewer. Furthermore, indirectness-induced mentalizing can extend to the interviewer's thoughts ("I wonder if she will see through this reply..."). The decision task given to active overhearers may also cause them to be more engaged across the board than in a more passive listening paradigm. If this causes all task-relevant neural systems to operate with increased 'gain' or 'intensity', comparable to what can be observed under attention-grabbing conditions in visual perception research (e.g., Vuilleumier, 2005), the differential effects of indirectness could be larger in our active overhearers. On the other hand, it is not necessarily the case that overhearers operate with reduced gain, as this also depends on whether what they are overhearing is interesting. ${ }^{2}$ In all, although there are various good reasons to predict a sizeable indirectness effect in the mentalizing network of active overhearers, the effect is not necessarily larger than that observed for passive overhearers.

\subsubsection{Other discourse-level cognitive processes}

Relative to direct replies, indirect replies should not only increase the cognitive perspective-taking load in active overhearers. For the same reasons as above, they also bring additional complexity at the level of inferring and dynamically representing a more complex situation model (e.g., listeners need to model not only that the candidate will perhaps take a language course this summer, but also that she is not fluent yet), a more complex model of the social situation (e.g., the candidate is evading the question), and perhaps the character of the candidate (e.g., she is trying too hard to get the job...). We predict that these additional discourse processing requirements will additionally engage bilateral temporal and frontal regions implicated in discourse-level cognitive processing, such as inferior frontal gyrus as well as anterior, middle and superior temporal lobes (e.g., Ferstl et al., 2008). As before, whether the extent of this differential activation will be larger or smaller in active as opposed to passive overhearers is difficult to predict, in part because the materials passively overheard in our earlier study (Bašnáková et al., 2014) are entirely different from the current materials.

\footnotetext{
${ }^{2}$ Note that, although passive overhearing is usually not overly 'engaging' in the average psycholinguistic experiment, this is by no means a necessary implication. Consider fictional narrative, the invented stories in films, TV-series and novels that allow us to overhear (imagined or physically enacted) conversations between protagonists, and as such provide us with massively engaging, and often emotionally moving experiences on a virtually daily basis (Boyd, 2009; Gottschall, 2012; Mar and Oatley, 2008). In research on how people process all that fiction, central concepts such as "transportation" (e.g., Green and Brock, 2000), "identification" (e.g. Cohen, 2001), "narrative engagement" (e.g., Busselle and Bilandzic, 2008), or "absorption" (e.g., Slater and Rouner, 2002) testify to the possibility that 'passive' overhearing can be highly involving.
} 


\subsubsection{Affective processes}

In our previous study (Bašnáková et al., 2014), face-saving indirect replies increased activity in the right anterior insula and ACC in passive overhearers relative to more direct replies, possibly indexing more affective perspective-taking (e.g., empathy, Bernhardt and Singer, 2012; Decety and Lamm, 2006; Fan et al., 2011) or some other affective stance. In the current paradigm, we also predict indirectness-induced additional activity in affect-related areas, albeit not for exactly the same reasons. Previously (Bašnáková et al., 2014), participants were passively overhearing a conversation wherein other people used indirectness to navigate some distant fictitious social world. In the job interview setting, however, the participant is evaluating the candidates, and should therefore have a natural interest in the information supplied by them, in the straightforwardness and truthfulness of their replies, and in what all that says about their character. Face-saving indirect replies can therefore easily lead to increased activity in affect-related areas (see Van Berkum, 2015, for a general analysis of how affect can permeate language comprehension). Most obviously, via appraisals such as "he's trying to fool us", evasive indirect replies can lead to such affective responses as, for example, irritation (what an annoying person), competitive playfulness (you won't win this way), respect (he's playing it smart) or compassion (how sad that he feels he needs to do this) - all the usual things that govern interpersonal interaction at the social level in everyday situations, too. Considering the diversity of specific affective responses in the current paradigm, we focus our predictions for an indirectness effect in brain areas associated with general emotional salience, notably anterior insulae and ACC (Barrett and Satpute, 2013). Whether the extent of affective responding in these areas is larger or smaller in active overhearers than in passive overhearers is impossible to predict, because of the many differences involved in this cross-study comparison.

\subsection{Predictions for active addressees}

\subsubsection{Cognitive perspective-taking and other discourse-level cogni- tive processing}

Just like active overhearers of a job interview, active addressees of an indirect reply in that setting need to do the groundwork of additional cognitive perspective-taking, to work out the conversational implicature (e.g., "no, not fluent yet"), and to construe currently important aspects of the speaker's social intention (e.g., "this candidate prefers to downplay absent qualifications, and may even want to fool me"). Furthermore, all such additional cognitive perspective-taking inferences lead to additional complexity to be represented in the situation model of what is being talked about, as well as in a model of the social situation and the candidate. We thus predict that face-saving indirect replies lead to increased activation in the same mentalizing and discourse-level cognitive processing related areas as predicted for active overhearers (and observed for passive ones).

\subsubsection{Affective processes}

Just like active overhearers in the job interview setting, active addressees are evaluating the candidates, and should therefore have a natural interest in the information supplied by them, in whether replies are straightforward and truthful, and in what this says about the candidate at hand. We therefore predict that facesaving indirect replies will elicit increased activity in affect-related areas such as insula and ACC, for the same reasons as with active overhearers. However, here we can also make a strong prediction about the size of the indirectness effect, because appraisals such as "he's trying to fool me with this reply" or "he seems to think that people like me can easily be misled" get very personal: it is the fMRI participant him- or herself that is being fooled, misled, or otherwise manipulated by the job applicant. We therefore predict that, at least for this reason, evasive indirect replies will be more emotionally salient for active addressees than for active overhearers, and will as such lead to stronger increases of activity in the emotional salience network (Barrett \& Satpute, 2013), as well as perhaps in other affect-related brain areas.

Taken together, the general prediction is that the pattern of findings obtained with passive overhearers (Bašnáková et al., 2014) will port to active overhearers and active addressees in a job interview setting, for the simple reason that the same types of additional processing needs to be done. So, relative to straightforward direct replies, face-saving indirect replies should lead to increased activity in mentalizing areas (at least mPFC and rTPJ, and possibly precuneus), in fronto-temporal areas dealing with other discourse-level cognitive complexity, and in affect-related areas (at least insula and ACC). Although arguments concerning additional involvement and 'increased gain' are tempting to make, we refrain from making strong specific predictions about the size and extent of those indirectness effects, except for one particular case: because the active addressee in the interview setting is the very person being 'manipulated' by the socially navigating speaker, we expect face-saving indirect replies to elicit stronger affect-related activations in addressees than in active overhearers.

\section{Materials and methods}

\subsection{General design}

To create a situation where posing questions and getting direct and indirect replies would be natural, we set up a mock job interview experiment. Each fMRI participant interviewed three job candidates for different jobs (teacher, manager, office assistant, researcher) and on the basis of their replies made a decision about whom to hire (a short example interview is in Appendix A). The participant was told that the three job candidates they were to interview were role-playing participants who already completed a similar session with another fMRI participant 'interviewer' the week before, and that he or she would now conduct a live second interview with them (active addressee condition), as well as listen to their earlier interviews (active overhearing condition). The fMRI participant was also told that the live interviews with each of the three job candidates had to be conducted over the intercom to those candidates in an adjacent room, "to make sure that any accidental differences in attractiveness between candidates would not influence the participant's choices". Each job interview was structured by means of a predefined set of questions, designed to help in choosing the best candidate. This allowed us to maintain tight experimental control over linguistic aspects of the critical replies across the two conditions: both replies that were given in the 'live' interview (active addressee condition) and in the "recorded" interview (active overhearer condition) were actually recorded earlier by the same native Dutch speakers, now played back at the right time by the experimenter. After the interviews were done, we excluded those fMRI participants who did not believe that they were talking to live people in the active addressee condition, from the analysis.

\subsection{Materials}

We constructed 120 replies and 240 questions: each reply served either as a direct reply or an indirect reply when preceded by its corresponding "direct" or "indirect" question. The indirect questions were yes/no questions, so that the listener was forced to interpret the reply as either a 'yes' or a 'no', which required inference from the actual reply. The direct questions were open- 
ended (why...? what...? etc.). Example stimuli are in Table 2, and the full set of written Dutch materials can be found in Supplementary materials.

The replies were recorded by three female Dutch native speakers (a third each) and all the questions were recorded by another female Dutch native speaker who acted as the interviewer in the overhearer condition. In order to preserve the dynamics of an interview, the recordings were carried out as if the two speakers were actually in an interview, i.e. the reply always followed a question. The speakers were instructed not to read the QA pairs during recordings, but to say them out of their memory. The final set of stimuli was edited in Praat (Boersma and Weenink, 2009), adjusting the volume and cutting the question-answer pairs into individual conversational turns. Questions started from the beginning of the first word and ended just after the last word, and replies were cut from the end of the preceding question, with the pre-utterance pause included.

Even though the direct and indirect replies were identical at the word- and sentence-level across conditions, we took great care in attenuating any possible differences between the conditions other than the replies' differences in implied message. We equated the direct and indirect questions on:

(i) length in the number of words (mean direct question $=12.81$, mean indirect question $=12.86$ ); (ii) the extent of direct semantic priming - i.e. how many content words from the question were repeated in the reply; (iii) loudness of the critical utterance across conditions; (iv) semantic similarity of the question and the reply. Semantic similarity was compared by means of latent semantic analysis (Landauer et al., 1998; Landauer and Dumais, 1997) (available online at http://lsa.colorado.edu). Since there are currently no reasonably large semantic corpora available in Dutch, we translated the stimuli into English and carried out the analysis in English. A term-to-term comparison of content words using tasaALL space, which corresponds to a reading level of a third-grade college student, yielded similar mean semantic similarity values (SSVs): direct $=0.65$, indirect $=0.66$.

We also carried out two pre-tests on different aspects of the stimuli. Firstly, 5 Dutch college-aged native speakers judged the QA pairs for "acceptability", which was defined as "the extent to which you find the reply acceptable" within the context of a job interview. Participants were supposed to judge the acceptability on a 5-point scale. We changed the QA pairs which yielded low ratings and an independent Dutch native speaker judged them again, until they were all acceptable. After that, we conducted an Indirectness pretest, where another group of 22 native Dutch college students judged, on a 7 -point scale $(1=$ completely direct, $7=$ completely indirect), to what extent the critical utterance was a direct or an indirect reply to the preceding question. There was a significant difference between the average rating for direct (2.84 (SD 0.91)) and indirect (5.65 (SD 0.66)) replies (paired-samples ttest, $p<0.001)$. In order to make the difference even more pronounced, we further changed items whose average difference in ratings for the direct and indirect version was less than 2.5 points.

Although the critical direct and indirect utterances were identical in their wording, there were small differences in the duration of each reply due to prosody, and in intonation. Mean duration of direct replies was $3.35 \mathrm{~s}$ (SD 0.80), and of indirect replies $3.62 \mathrm{~s}$ (SD $1.03)$, a statistically significant difference $(p<0.001)$. Also the preutterance pause was, on average, longer for the indirect replies. We deliberately chose not to make these acoustic delivery properties uniform or to use a single token of the utterance in both conditions, as this would compromise the naturalness of our materials.

We also constructed 147 filler items with mostly open-ended questions (such as wh-questions) and direct replies. Filler items were purposefully imperfect, with dysfluencies, repairs, false starts, etc., to convey the impression that the candidates were speaking in real time.

We created two stimulus lists with the final stimulus set - half of the participants were presented with list $A$ in the overhearer condition and list B in the addressee condition, and vice versa (so that a participant would never hear the same reply twice). Each list contained 30 direct and 30 indirect replies and the rest were fillers. Once again, even though the target utterances - the replies - were identical for both direct and indirect conditions, and served as their own controls, we made sure that important psycholinguistic variables were as balanced as possible in both versions of the stimulus lists for both direct and indirect conditions: lexical frequency of content words in the target utterances, number of words per direct/indirect questions and direct lexical priming (repetition of the same content words from question to reply).

Finally, we created another 60 single sentences for a "noncommunicative control" condition, matched on word count (version $A=10.07$ (SD 2.48), version $B=10.07$ (SD 2.36)) and lexical frequency of content words $(A=3.40(0.31), B=3.41(0.37))$. There was an "addressee" control which was presented after the addressee part of the job interview, and an overhearer control. In each of these conditions, participants were instructed to simply listen for meaning to a set of 30 isolated sentences, spoken by the candidates but unrelated to the interview. In the addressee condition, they were told to "listen to the candidates reading these sentences for you", and in the overhearer condition, they were told to "listen to these sentences recorded at a previous session with the candidates". This provided us with a way to probe the addressee/overhearer distinction at a very basic level of somebody speaking directly to you right there and then, as opposed to hearing a recording, without a richer social context that turns it into useful communication.

\subsection{Procedure}

We communicated the study as a social decision-making study to the participants. We took several measures to make the "addressee" manipulation convincing. Starting with the recruitment information, we pretended to look for 4 persons per session, with one playing the role of the interviewer (the actual participants) and the rest the role of "job candidates". Before the session, we emailed the fMRI participant that they were chosen for the role of the interviewer, asking them not to come earlier to their appointment, as to not meet the rest of the participants ("job candidates") at the door. In addition, before the addressee part of the session, the experimenter pretended to call her colleague in the adjacent room to find out whether the three job candidates were ready, and she then proceeded to a "sound check", in which each of the candidates and the actual participant tested their microphones. The candidates' voices for the sound check were recorded and manually triggered by the experimenter. As for the content of the candidates' replies, we told the fMRI participant that each candidate had a rough outline of what his character was like (skills, knowledge, experience) but was free to improvise to some extent. However, candidates could not lie, e.g. say that they have certain skills when in fact they don't.

Both addressee and overhearer parts of the interview took place on one day, with their order of presentation counterbalanced across participants. Each part was followed by a short control run (described above), where the fMRI participant heard 30 sentences from the candidates (10 each). After the participants came out of the MRI scanner, they took part in an exit interview.

Each interview (in both addressee and overhearer conditions) followed the same pattern: first, a short job advertisement was projected on the screen, stating the requirements for a specific job. There were four positions in each part (teacher, manager, 
researcher and office assistant). When the participant was ready, the interview started. There were 11 or 12 questions for each candidate, which the fMRI participants either read out loud themselves from the computer screen (addressee condition) or listened to them through headphones and saw them projected on the screen at the same time (overhearer condition). The participants were asked to press a button with their right index finger when they were finished with reading or listening, to indicate that they were ready for the answer. The button-press triggered the recorded reply after a $1.5 \mathrm{~s}$ delay. After each candidate answered their set of questions, the fMRI participant was to indicate on a 7-point scale how much he or she liked the candidate, how much he or she thought this candidate was suitable for the job, and how much this candidate was similar to him or her. Then, the next candidate followed. When all three candidates were interviewed (either by the participant or by another interviewer), the fMRI participant was asked to choose the best one for the job and then verbally indicate the reason for this choice. He was instructed to say whatever he finds relevant to support his choice and in the addressee condition, he was assured that the candidates cannot hear his judgment. This was done in order to make the two conditions as similar as possible. After the decision, the next job advertisement and round of interviews followed.

The composition of each experimental trial was as follows: a fixation cross was projected in the middle of the screen for a variable time interval between 1.3 and $3.3 \mathrm{~s}$. Then, a question was displayed, terminated by a button-press. The length of the question duration was variable, as it depended on how fast participants read it (as addressees) or how long it took them to comprehend the spoken questions (as overhearers). A fixation cross appeared on the screen for a variable time interval between 1.6 and $4.6 \mathrm{~s}$, which included a pre-utterance pause before the replies. The fixation cross stayed on the screen during the critical event - the reply - which was presented auditorily, followed by 1.5 seconds of silence. The replies lasted on average 3.49 s (SD 0.93, range 1.767.99). The entire session lasted for $2-2.5 \mathrm{~h}$.

After the session, we conducted an exit interview with the fMRI participants. Here, we asked them whether they felt any subjective differences between interviewing the candidates themselves and listening to another person interviewing them (e.g. whether it was more difficult to make their decisions), whether they noticed any "evasive" replies, understood all the replies, and found any of the candidates more likeable than others. We also asked them to tell us whether they noticed anything strange and gave them the opportunity to ask us anything they wanted to know about the entire study. As the last "credibility check" of our addressee manipulation, we asked them whether they now wanted to meet the candidates in person. Only a few participants wanted to - to those, we pretended to look for the candidates and then told the participants that they've already left. Out of the 30 fMRI participants, 8 indicated in the exit interview that they did not believe they interacted with real people. These were debriefed about the purpose of the study immediately. The rest was debriefed via e-mail after the study was finished.

\subsection{Participants}

30 students participated in the experiment for money or course credit and 20 of them were included in the final analysis (4 male, mean age 20.8, SD 2.6). Eight participants were excluded because they did not believe in the "addressee" manipulation and two because of other reasons (one had difficulties reading and comprehending the questions, one did not finish all the runs in the required order).

\section{5. fMRI data acquisition}

Participants were scanned in a Siemens 3-T Tim-Trio MRIscanner using an 8 channel surface coil. Functional images were acquired using an EPI multi-echo sequence (Poser et al., 2006) in an ascending order. The repetition time (TR) was $2.35 \mathrm{~s}$ and each volume consisted of 36 slices of $3-\mathrm{mm}$ thickness with a $17 \%$ slice gap. The voxel size was $3.5 \times 3.5 \times 3 \mathrm{~mm}^{3}$, and the field of view was $224 \mathrm{~mm}$. Functional scans were acquired at 4 different echo times $(\mathrm{TE} 1)=9.4 \mathrm{~ms},(\mathrm{TE} 2)=21.2 \mathrm{~ms},(\mathrm{TE} 3)=33 \mathrm{~ms},(\mathrm{TE} 4)=45 \mathrm{~ms}$ Flip angle was $90^{\circ}$. A whole-brain high-resolution structural T1weighted GRAPPA sequence was performed to characterize participants' anatomy $(\mathrm{TR}=2300 \mathrm{~ms}, \mathrm{TE}=3.03 \mathrm{~ms}, 192$ slices with voxel size of $1 \mathrm{~mm}^{3}$, field of view=256).

\section{6. fMRI data analysis}

The functional magnetic resonance imaging (fMRI) data were preprocessed and analyzed using Statistical Parametric Mapping (SPM8, fil.ion.ucl.ac.uk/spm/). The first pre-task 30 volumes were acquired and used for weight calculation of each of the echoes. The functional echo-planar imaging-BOLD images were then realigned and slice-time corrected. The resulting functional images were coregistered to the participants' anatomical volume based on the subject-mean functional image, normalized to MNI space, and spatially smoothed using a 3-dimensional isotropic Gaussian smoothing kernel (full-width half-maximum $=8 \mathrm{~mm}$ ). A temporal high-pass filter was applied with a cycle cutoff at $128 \mathrm{~s}$.

In the first-level linear model, we modeled the onsets and durations of the 4 types of the target utterances (direct reply addressee, indirect reply addressee, direct reply overhearer, indirect reply overhearer), which were defined from the start of speaking (not including the pre-utterance pause), including the entire reply and $1.5 \mathrm{~s}$ of silence at the end of it. Each condition included 30 trials. We also modeled the onset and duration of the visually presented fixation crosses before each question as a baseline. Since the overhearer and addressee conditions were measured in separate runs with a break in between, the baseline included fixation periods from both sessions. We did this in order to account for any potential differences in the baseline between these two runs. In addition, we modelled the onsets and durations of the questions. In a separate analysis of the control sentences, we modeled onsets and duration of each control sentence and a fixation cross preceding the sentence. The regressors were convolved with a canonical hemodynamic response function, and the realignment parameters were included in the model to correct for subject movement during scanning. Subsequently, the following images were defined for each participant and used in the second-level random effects analysis: indirect reply $>$ fixation cross baseline and direct reply $>$ baseline (in both overhearer and addressee conditions), as well as control sentence $>$ fixation cross in both addressee and overhearer control conditions.

In the second-level random effects analysis, we used the contrast images of interest (reply $>$ baseline) in a repeated-measures flexible-factorial model with Listener Status (addressee, overhearer), indirectness (direct, indirect) and Subjects as factors. The cluster size was used as the test statistic, and only clusters significant at $p<0.05$ corrected for multiple non-independent comparisons are reported. The initial threshold was 0.001 at the voxel level.

\subsection{Region-of-interest analyses}

To test our predictions about cognitive perspective-taking, additional discourse-induced cognitive processing, and affective processing with more statistical power, we conducted several 
Region-Of-Interest (ROI) analyses. The first one included 4 ROIs that are considered core nodes of the mentalizing or ToM network (e.g. Schurz et al., 2013; Mar, 2011): left and right temporo-parietal junction (TPJ), medial prefrontal cortex (MPFC) and precuneus (PC). The coordinates were taken from a recent meta-analysis on ToM by Van Overwalle and Baetens (2009): right TPJ: $x=50$, $y=-55, z=25$; left TPJ: $x=-50, y=-55, z=25$; MPFC: $x=0$, $y=50, z=20$; and PC: $x=0, y=-60, x=40$. Second, to asses additional discourse-induced cognitive processing, we chose two sets of areas routinely activated in studies that go beyond sentence-level meaning comprehension: bilateral anterior temporal lobes (ATL) and bilateral inferior frontal cortex. Bilateral ATL is the most stably activated part of the extended language network (Ferstl et al., 2008) observed in text comprehension research, and was also sensitive to implied speaker meaning in another study on conversational implicature comprehension with indirect replies (Jang et al., 2013). ATL coordinates were taken from the latter study: left ATL: $x=-50, y=8, z=-24$; right ATL: $x=54, y=0$, $z=-20$. Coordinates for bilateral IFG, both BA 45 and 47 , were taken from Hagoort et al. (Hagoort et al., 2004): left BA45 $x=-44$, $y=30, z=10$; right BA45: $x=44, y=30, z=10$; left BA 47: $x=-48$, $y=30, z=13$; right BA47: $x=48, y=30, z=-13$. These areas were sensitive to world-knowledge anomalies in the Hagoort et al. study, and (apart from left BA45) also involved in unifying generic world-based scenario knowledge with specific discourse-context constraints in a follow-up study (Menenti et al., 2009).

The third ROI analysis investigated the ventral salience network (Barrett and Satpute, 2013) with bilateral anterior insulae (AI) and pregenual anterior cingulate cortex (pACC). Coordinates for this analysis were taken from a resting state connectivity study by Taylor et al. (2009): L anterior insula: $x=-34, y=14, z=2$; R anterior insula: $x=36, y=16, z=2$; left pACC: $x=-8, y=38, z=19$; right pACC: $x=8, y=38, z=19$.

Using the MarsBaR toolbox for SPM (Brett et al., 2002), we extracted mean signal from an 8-mm spherical ROI around each of these peak coordinates and subjected them to repeated-measures ANOVAs in SPSS (version 23) with ROI, Listener Status and Indirectness as within-subject factors.

\section{Results}

We report main indirectness effects and interactions with the active overhearer/addressee factor in a whole brain analysis first, and then report results of ROI analyses in the networks of interest.

\subsection{Main effect of indirectness}

Comparing the indirect with direct replies across both addressee and overhearer conditions (indirect > direct, see Fig. 1 and Table 1) engaged a bilateral fronto-temporal network of areas which largely overlapped with the comparison between facesaving and direct replies in our previous study on processing indirect replies (see Fig. 2c, reprinted from Bašnáková et al., 2014). In the current study, indirectness elicited bilateral activations in the inferior frontal gyri and anterior insulae; in the middle and superior temporal gyri, extending into the temporal poles. Moreover, there were bilateral activations in the angular gyri (TPJ), and superior medial frontal gyri, extending into ACC. Unlike in the previous study, the indirectness effect also activated subcortical

${ }^{3}$ The emotional salience (Taylor et al., 2009) and mentalizing (Van Overwalle and Baetens, 2009) sets of coordinates were first converted from the Talairach to the MNI space using the tal2mni transform script implemented in Matlab. Discourse-level processing coordinates from Hagoort et al. (2004) are reported in MN space.

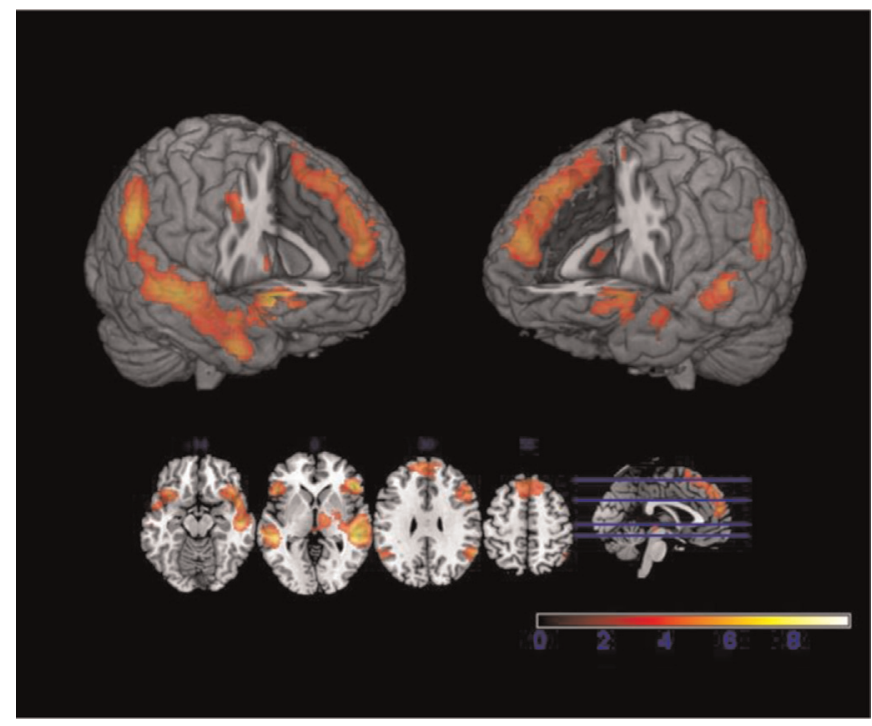

Fig. 1. Brain areas activated for the Indirectness effect (contrasting indirect $>$ direct replies) in the current study across both addressee and overhearer conditions. Significant effects are displayed on cortical renderings and on axial slices ( $z$ coordinate levels are in millimeters: $-14,0,30,55$ ). Color bar denotes $t$-values (in blue). (For interpretation of the references to color in this figure legend, the reader is referred to the web version of this article.)

regions in the right hemisphere, namely thalamus and pallidum.

\subsection{Interaction between listener status and indirectness}

At the level of the whole brain analysis, the processing consequences of indirectness did not significantly depend on whether the participant was an addressee (Fig. 2A) or an overhearer (Fig. 2B). There were no significant clusters activated for the interaction at the $p<0.001$ threshold at both sides of the interaction ( $t$-contrasts).

\subsection{Region of interest analysis}

As illustrated in Fig. 3A, we did not find any evidence that critical regions implicated in cognitive perspective-taking respond differently to indirectness depending on whether the participant is directly addressed or is actively overhearing them. For this mentalizing ROI analysis, there were significant main effects of Indirectness $(F(1,19)=14.87, p=0.001)$ and Listener Status $(F(1,19)=$ $7.79, p=0.012)$ but no interactions $(F(1,19)=0.23, p=0.635$; Listener Status with Indirectness and ROI: $F(3,57)=6.84, p=0.089)$. Thus, although there was greater activity for indirect than direct replies in all four regions of interest, the size of this indirectness effect in these areas did not reliably depend on whether the participant was overhearing or being addressed.

A similar pattern of results was obtained in the two ROI analyses aimed at discourse-level cognitive processing regions in the fronto-temporal network, see Fig. 3B. The bilateral ATLs showed greater activation for indirect than for direct replies $(F(1,19)=$ $35.10, p<0.001)$, but the size of this indirectness effect did not reliably depend on listener status $(F(1,19)=0.03, p=0.875)$, in none of the ROIs $(F(1,19)=0.54, p=0.473)$. Likewise for the bilateral IFG (BA45 and BA47): greater activation for indirect than for direct replies $(F(1,19)=34.16, p=<0.001)$, in a way that depended on ROI (indirectness $\times$ ROI interaction, $F(3,57)=9.62, p=0.001$, after Greenhouse-Geisser correction), but again no reliable impact of listener status on the size of this indirectness effect $(F(1,19)=$ $0,19, p=0.669)$, for any of the ROIs $(F(3,57)=0.23, p=0.801$, Greenhouse-Geisser corrected). 
Table 1

Brain areas activated in the contrast indirect $>$ direct, cluster size $p$-value 0.001 (cluster-level FWE corrected).

\begin{tabular}{|c|c|c|c|c|c|}
\hline \multirow[t]{2}{*}{ Anatomical region } & \multicolumn{3}{|c|}{$\begin{array}{l}\text { Coordinates of local } \\
\text { maxima }\end{array}$} & \multirow[t]{2}{*}{ Cluster size } & \multirow{2}{*}{$\begin{array}{l}p \text {-Value (clus } \\
\text { ter-level FWE } \\
\text { corrected) }\end{array}$} \\
\hline & $\boldsymbol{x}$ & $y$ & $z$ & & \\
\hline $\begin{array}{l}\mathrm{R} \text { middle temporal } \\
\text { gyrus }\end{array}$ & 50 & -26 & -6 & 9242 & $<0.001$ \\
\hline \multirow{2}{*}{$\begin{array}{l}\mathrm{R} \text { inferior frontal gyrus } \\
\text { (p. triangularis) }\end{array}$} & 52 & 26 & 4 & & \\
\hline & 40 & 20 & 30 & & \\
\hline $\mathrm{R}$ medial temporal pole & 48 & 6 & -34 & & \\
\hline $\mathrm{R}$ angular gyrus (TPJ) & 60 & -56 & 34 & & \\
\hline $\begin{array}{l}\text { R superior temporal } \\
\text { gyrus }\end{array}$ & 60 & -16 & 0 & & \\
\hline $\begin{array}{l}\text { R superior temporal } \\
\text { pole }\end{array}$ & 52 & 8 & -14 & & \\
\hline $\begin{array}{l}\mathrm{R} \text { inferior frontal gyrus } \\
\text { (p. opercularis) }\end{array}$ & 48 & 18 & 32 & & \\
\hline $\mathrm{R}$ precentral gyrus & 44 & 8 & 48 & & \\
\hline $\mathrm{R}$ thalamus & 10 & -10 & 2 & & \\
\hline $\mathrm{R}$ insula & 34 & 18 & -12 & & \\
\hline R pallidum & 30 & -14 & -6 & & \\
\hline $\mathrm{R}$ middle frontal gyrus & 42 & 4 & 42 & & \\
\hline $\mathrm{R}$ thalamus & 12 & -14 & -4 & & \\
\hline $\begin{array}{l}\text { thalamus, extending } \\
\text { into pallidum }\end{array}$ & 0 & -26 & -2 & & \\
\hline \multirow{6}{*}{$\begin{array}{l}\text { L medial superior fron- } \\
\text { tal gyrus }\end{array}$} & -2 & 48 & 38 & 3268 & $<0.001$ \\
\hline & -4 & 50 & 34 & & \\
\hline & -8 & 34 & 56 & & \\
\hline & -10 & 52 & 34 & & \\
\hline & 2 & 56 & 20 & & \\
\hline & 2 & 34 & 52 & & \\
\hline \multirow{4}{*}{$\begin{array}{l}\text { R medial superior fron- } \\
\text { tal gyrus }\end{array}$} & 4 & 44 & 44 & & \\
\hline & 12 & 60 & 24 & & \\
\hline & 12 & 62 & 20 & & \\
\hline & 2 & 46 & 38 & & \\
\hline $\begin{array}{l}\text { L supplementary motor } \\
\text { area }\end{array}$ & -12 & 10 & 68 & & \\
\hline $\begin{array}{l}\text { R supplementary motor } \\
\text { area }\end{array}$ & 16 & 28 & 56 & & \\
\hline \multirow{2}{*}{$\begin{array}{l}\text { L inferior frontal gyrus } \\
\text { (p. triangularis) }\end{array}$} & -54 & 20 & 10 & 1829 & $<0.001$ \\
\hline & -46 & 26 & -2 & & \\
\hline \multirow{3}{*}{$\begin{array}{l}\text { L inferior frontal gyrus } \\
\text { (p. orbitalis) }\end{array}$} & -36 & 20 & -14 & & \\
\hline & -46 & 32 & -4 & & \\
\hline & -40 & 24 & -10 & & \\
\hline \multirow[t]{2}{*}{ L temporal pole } & -38 & 16 & -18 & & \\
\hline & -48 & 2 & -24 & & \\
\hline $\mathrm{L}$ middle temporal & -52 & 4 & -14 & & \\
\hline \multirow{2}{*}{$\begin{array}{l}\text { L middle temporal } \\
\text { gyrus }\end{array}$} & -52 & -28 & -6 & 1382 & $<0.001$ \\
\hline & -48 & -36 & 0 & & \\
\hline \multirow{2}{*}{$\begin{array}{l}\text { L superior temporal } \\
\text { gyrus }\end{array}$} & -44 & -26 & 10 & & \\
\hline & -44 & -28 & 14 & & \\
\hline \multirow[t]{2}{*}{ L angular gyrus (TPJ) } & -58 & -58 & 26 & 519 & 0.008 \\
\hline & -56 & -58 & 40 & & \\
\hline $\begin{array}{l}\text { L middle temporal } \\
\text { gyrus }\end{array}$ & -54 & -56 & 22 & & \\
\hline
\end{tabular}

The ROI analysis for the affective ventral salience network revealed a very different pattern of findings. Although there was a trend towards a main effect of indirectness $(F(1,19)=4.23$, $p=0.054$ ) in these areas, the pattern is dominated by an interaction $(F(1,19)=6.08, p=0.023)$, see Fig. 3C: indirectness increased activation in these areas when people were themselves addressed, but not when they were overhearing the indirect replies.

In line with the aims of our study, we focus on the differential impact of face-saving indirectness and its modulation by listener status. Although our design is less optimal for examining main effects of listener status (addressee > overhearer and vice versa), a report on the latter, as well as on results for a related non-communicative control condition, can be found in Supplementary materials.

\section{Discussion}

We examined an ingredient of language comprehension that, although critical, has not received all that much attention from researchers in the neurobiology of language field - how listeners arrive at the real speaker meaning, beyond the literal code. Building on our prior fMRI study on pragmatic inferences behind indirect replies (Bašnáková et al., 2014), we extended the work in two directions. Firstly, we moved from a paradigm in which listeners were passively overhearing bits of conversation towards a paradigm in which listeners needed to really comprehend those bits of conversation for further decision-making, a dominant mode of language use in the real world. To that end, we created a mock job interview setting, where the fMRI participant needed the information gleaned from direct and face-saving indirect replies to make decisions about which job candidates to hire. In addition to this active overhearer condition, our second extension was to compare the impact of face-saving indirect language use to that of the same utterances in active addressees. In the relevant condition, fMRI participants believed they were themselves interacting with the job candidate, and that direct and indirect replies were thus addressed to them.

\subsection{Indirectness when actively overhearing}

First, what is the differential impact of a face-saving indirect reply when actively overheard? We had predicted increased activation in core nodes of the mentalizing or ToM network, at least those observed in our earlier study (MPFC and TPJ), and possibly also other ones (e.g., precuneus). This is exactly what we observed. In the whole brain analysis, indirect replies induced additional activation in MPFC and right TPJ. In a more powerful region-ofinterest analysis that examined the four most typically activated mentalizing regions (mPFC, bilateral TPJ and precuneus; Schurtz et al., 2014; Van Overwalle and Baetens, 2009; Mar, 2011), all of these predesignated areas were recruited more by indirect replies than by direct replies. This is in line with theoretical analyses in pragmatics (e.g. Grice, 1975) according to which the comprehension of what speakers really mean requires a consideration of their communicative intentions, which inevitably involves taking their perspective into account.

The mentalizing network highlighted here also shows up in other studies on the comprehension of speaker meaning in overhearers, albeit not always to the same extent (e.g., Bašnáková et al. 2014: mPFC and right TPJ; Van Ackeren et al., 2012: mPFC and bilateral TPJ; see also Hervé et al., 2013; Li et al., 2014). All four nodes, including the precuneus, were activated in a recent study on the comprehension of speaker meaning in ironic utterances (e.g., "Tonight we gave a superb performance" said by one opera singer to another after a disastrous performance; Spotorno et al., 2012). The same four nodes were more strongly activated by referentially ambiguous pronouns (as in "When Beyoncé met Madonna she had just had a little accident at the hairdressers") than 
Table 2

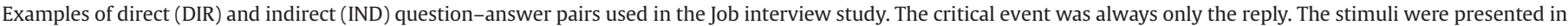
Dutch.

DIR: What is, in your opinion, the biggest shortcoming of internships?

IND: During your internship, have you worked independently on any big projects?

Interns do not usually get really important projects to work on.

DIR: What inspired you to go into people management?

IND: Have you followed any certified courses on leadership?

I've read a couple of very inspiring books about leadership.

DIR: How and when did you acquire basic command of German?

IND: You say that you are fluent in German. Have you followed any certified courses?

I've read a lot of books in German during college.

DIR: What was the biggest hurdle in getting funding for your PhD?

IND: Have you received any grants or scholarships during your studies?

The competition for scholarships in my field is extremely harsh.

in unambiguous controls (compared to, e.g. "When Beyoncé met Prince she had just had a little accident at the hairdressers"; Nieuwland et al., 2007). The latter suggests, in line with pragmatic analyses, that cognitive perspective-taking is not just needed for deriving rich conversational implicatures in indirect or ironic statements, but is also involved in more 'mundane' aspects of utterance comprehension, such as fixing the referent of a pronoun. This supports an important point we already made: although we use indirectness as a way to uncover the neural substrate involved in the inferential side of language comprehension, cognitive perspective-taking presumably occurs with any contextualized utterance, for the simple reason that listeners will want to know what the speaker is really talking about, and what his or her social intentions are.

People have noted that the areas implicated in mentalizing strongly overlap with nodes of the default-mode network (DMN) that is active when participants are not performing a specific task, e.g. during rest periods (e.g., Buckner et al., 2008). However, this overlap may not be a coincidence - it has been suggested multiple times (e.g. Mars et al., 2012; Schilbach et al., 2008) that when participants do "nothing" during rest periods, they are presumably doing precisely what is characteristic of social cognition - engaging in self-referential thinking, musing on what others' have said or done to them, and planning future social action. Also, a more generic explanation of our findings in terms of particular task conditions being more difficult than others and as such pulling more resources away from the brain's "default state" (a possibility that is sometimes considered when comparing task condition effects regardless of whether they involve social cognition) would need to suppose that the direct reply is more difficult than the indirect reply. In all, we believe that an explanation in terms of additional cognitive perspective-taking is currently the most plausible one for our indirectness effect in TPJ, MFC and PC.

Our second prediction was that actively overheard indirectness would also increase activity in fronto-temporal areas known to be sensitive to other cognitive implications of additional complexity in rich discourse situations, such as bilateral frontal and temporal regions implicated in semantic processing, causal inferencing, working memory and executive processes (e.g., Bohrn et al., 2012; Ferstl et al., 2008; Ferstl and von Cramon, 2002; Kuperberg et al., 2006; Rapp et al., 2012; Menenti et al., 2009). Recall that an indirect reply such as "I am planning to take a language course this summer" brings additional complexity to the 'situation model' (e.g., the listener needs to add that the candidate will perhaps take a language course this summer, and that she is not fluent yet), as well as to representing the candidate at a more social level (e.g., is evading the question, is trying too hard). Our findings confirm this prediction as well. In the whole brain analysis for active overhearers, indirect replies increased activation in bilateral IFG and bilateral temporal regions, results that were echoed in our more sensitive region-of-interest analysis on BA45, BA47, and ATL. We return to these areas when we discuss the findings for active addressees.

Based on our earlier results as well as a conceptual analysis of the current active overhearing situation, we had also predicted an indirectness effect in nodes of the affective ventral salience network (Barrett and Satpute, 2013), notably anterior insular cortex and pregenual ACC. In the regions of interest analysis, this prediction did not hold up. This is surprising, because in a job interview setting, indirect replies can easily be assumed to lead to emotion-inducing appraisals of the speaker's evasive move (irritation, sympathy, etc.). One might be tempted to pursue the idea that active overhearers approach matters in a relatively balanced way in the current paradigm, such that they find straight answers as affectively (un)engaging as face-saving ones, without being sensitive to the potentially affective overtones of the latter. Note, however, that in the whole brain analysis, face-saving indirectness did increase activity in other areas commonly associated with affect, namely slightly more dorsal region of right insula.

\subsection{Indirectness when being addressed}

An important benefit of our current paradigm is that it also allows us to compare, within a single study and with the same participants, what face-saving indirectness does with listeners who believed they were actually being addressed, as opposed to active overhearing the same indirect utterances. Just like active overhearers, active addressees of an indirect reply need to do the groundwork of additional cognitive perspective-taking, to work out the conversational implicature (e.g., that "I am planning to take a language course this summer" also means "no, not fluent yet"), as well as the speaker's social intention (e.g., "this candidate prefers to downplay absent qualifications, and may even want to fool me"). We therefore predicted that face-saving indirect replies should in any case increase activation in core nodes of the mentalizing network of active addressees as well. This first prediction was confirmed, by increased activation for indirect replies in all ROI-targeted regions: medial PFC, bilateral TPJ, and precuneus (see Fig. 3A).

Interestingly, both the whole brain analysis and the more sensitive region-of-interest analysis also revealed that in the current job interview paradigm, the core nodes of the mentalizing network do not reliably care whether the indirect utterance is overheard or directly addressed to you. All of these areas were more highly activated for indirect than for direct replies, in both the addressee and overhearer conditions, and the size of the indirectness effects in those areas did not reliably depend on whether one was overhearing or being addressed. This is in line with our idea that in comprehension, the same mentalizing groundwork needs to be done in either case. Moreover, it suggests that 

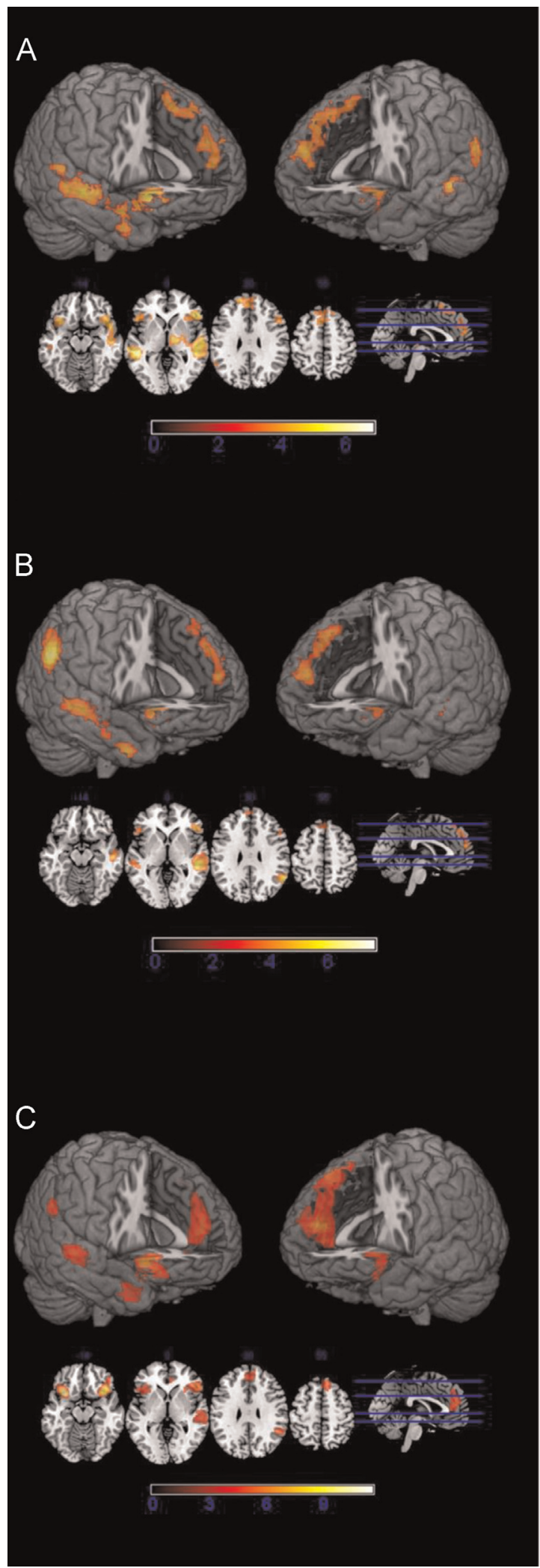

Fig. 2. Brain areas activated for the Indirectness effect (indirect face-saving $>$ direct replies) in (A) active addressees and (B) active overhearers, of the current study, and (C) passive overhearers in the Bašnáková et al. (2014) study. Even though graphical comparison seems to suggest a lateralization difference in the temporo-parietal area, there is no interaction at the whole brain level. Significant effects are displayed on cortical renderings and on axial slices ( $z$ coordinate levels are in millimeters: $-14,0$, $30,55)$. Clusters are shown at a threshold of 0.001 voxel level and extent of $>200$ voxels. Color bars denote $t$-values (in blue). (For interpretation of the references to color in this figure legend, the reader is referred to the web version of this article.) these components of the comprehension system do not necessarily operate with increased gain just because somebody is being addressed.

Active addressees and active overhearers also do not differ in how they respond to face-saving indirectness in fronto-temporal regions associated with other language-induced cognitive operations (e.g., bilateral IFG, bilateral MTG, right STG, and right temporal pole), neither in the whole-brain analysis, not in more targeted ROI analyses. In these latter analyses, indirect replies induced additional activations in left and right IFG (BA45 and BA47), and in left and right ATL. Furthermore, as illustrated clearly in Fig. 3B, these differential effects of indirectness in active addressees were not reliably different from those in active overhearers.

The involvement of bilateral inferior frontal gyrus is consistent with the idea that the comprehension of indirect replies requires intensified consideration of the context, such as the preceding question, the wider discourse, and the social rules that we obey when talking to each other. This area has been involved in studies on both sentence (Hagoort et al., 2009) and discourse-level processing, such as making causal inferences (Kuperberg et al., 2006) or in supporting semantic selection of inferential information (Mason and Just, 2011). The right IFG, specifically, has been related to the difficulty of integrating incoming information into context (e.g. Tylén et al., 2009; Wang et al., 2006; Tesink et al., 2009; St George et al., 1999).

Anterior temporal lobes are also found in many studies on discourse-level processing (see the extended language network (ELN), Ferstl and von Cramon, 2002). Recently, a study on the interpretation of conversational implicatures has highlighted this region as sensitive to the level of implicitness of the speaker's message (Jang et al., 2013). On a lower-level of processing, ATLs are considered a domain-general semantic hub (e.g. Visser and Lambon Ralph, 2011) but a recent review by Wong and Gallate (Wong and Gallate, 2012) of literature on ATLs and processing of socially relevant stimuli suggests that this region could nevertheless be biased towards processing social information or personally relevant stimuli.

Middle and posterior temporal cortices are also part of the ELN, where they are ascribed a role of in integration and interpretation of language. Right middle temporal cortex is commonly seen in tasks going beyond literal meaning of utterances, including figurative language processing such as metaphors (Bottini et al. 1994), or idiomatic expressions (Lauro et al., 2008; Proverbio et al., 2009; Zempleni et al., 2007). Findings by Kuperberg et al. (2000) and Kircher et al. (2001) indicate that right middle and superior temporal regions might be sensitive to the ease of semantic integration.

Taking a step back, we have seen that in the current job interview paradigm, the neural systems involved in cognitive perspective-taking (mPFC, TPJ, precuneus) and in other cognitive operations associated with more complex discourse (IFG, ATL) are both responsive to face-saving indirectness, in a way that does not depend on whether the participant is being addressed or merely overhearing. However, as for core nodes in the affective ventral salience network, bilateral anterior insulae and ACC, things are a little different. For active addressees, we had not only predicted an indirectness effect in these areas, but also a stronger indirectness effect here in addressees than in active overhearers. After all, evasive or otherwise 'manipulative' indirect replies can be expected to elicit a stronger emotional response if you are the target of such social navigation than when the replies are directed at somebody else. Both predictions were clearly confirmed. As can be seen in Fig. 3C, face-saving indirect replies reliably increased activity in the anterior insulae and ACC when participants were being addressed, and did so much more than when they were 

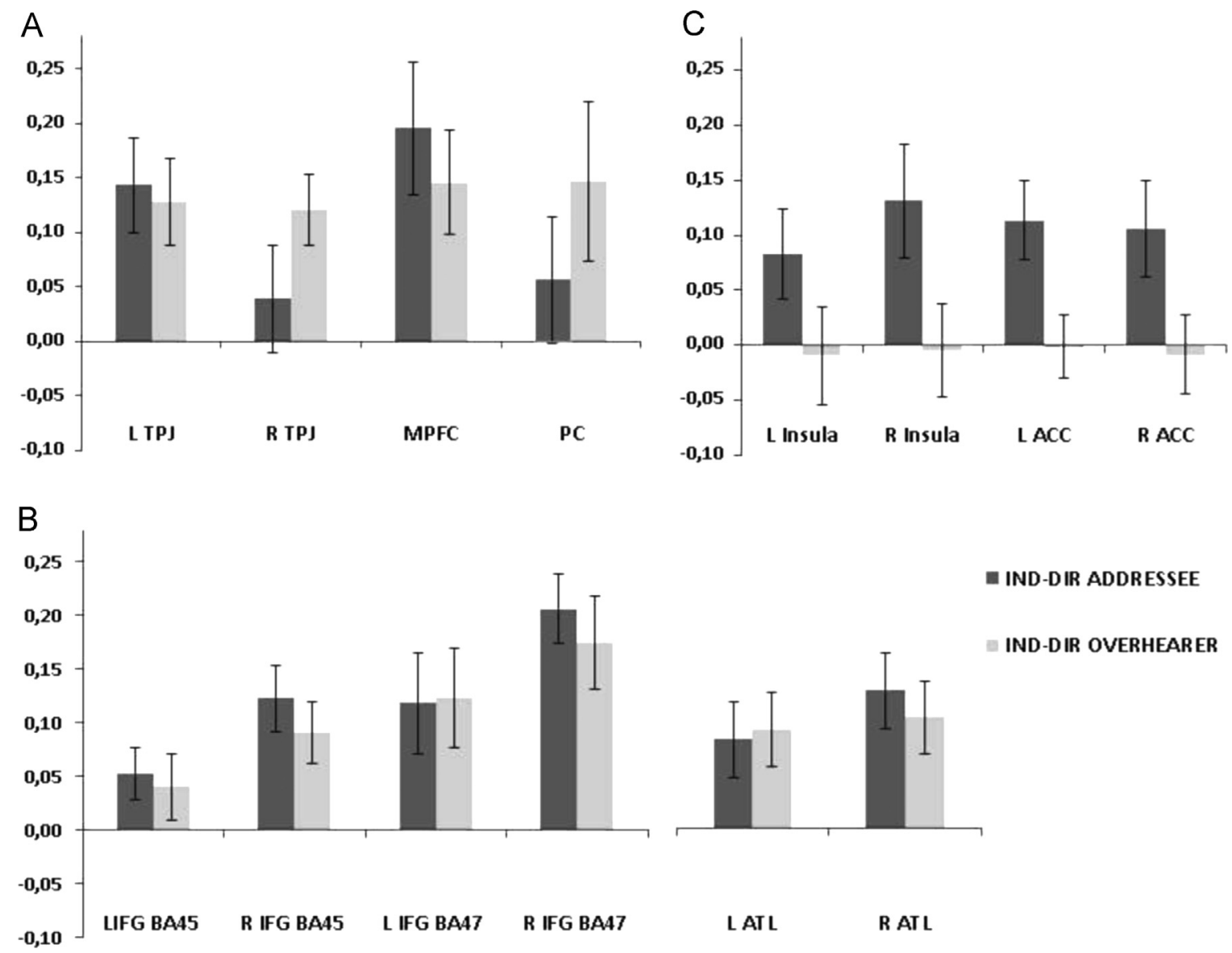

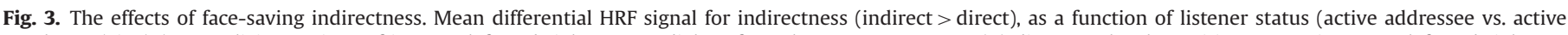

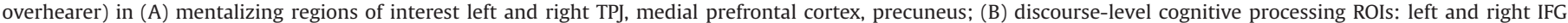

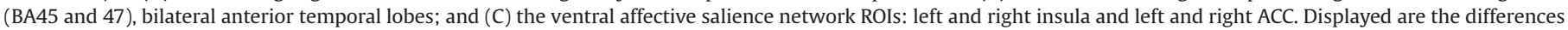
in average beta values between indirect replies and direct replies at each ROI. Error bars indicate SEM.

overhearing (no effect of indirectness).

In the light of the ROI findings in the more cognitive areas displayed in Fig. $3 \mathrm{~A}$ and $\mathrm{B}$, the ventral salience network result displayed in Fig. $3 \mathrm{C}$ is interesting, for various reasons. First, it suggests that indirectness does not additionally activate every area inspected in a powerful ROI analysis. It is also interesting because for participants, there was no functional difference in the task between the two conditions: in both situations, they really only needed to extract the relevant information, compare them to their expectations about a perfect candidate, and make an informed judgment. What our findings suggest, however, is that this is not the whole story: being addressed does change things, not so much because of changes at the referential level (what is being talked about), but because the social configuration is different. With the current paradigm lacking visual contact (i.e., lacking feedback from gestures or facial expressions) and true relevance for participants (such as bearing the consequences for a badly chosen employee), these social-affective differences between being addressed and overhearing are bound to be much larger in real life.

How crucial is the emotional involvement in interpreting indirect replies, observed in addressees, to the enterprise of understanding language comprehension? Is it a mere downstream affective consequence of "getting the message" - feeling in a particular way about how the candidate handled a sensitive question? Or is it an inextricable part of the interpretation process, a "hot" addition to the primarily "cold" analysis of speaker meaning? We have no means to disentangle these two positions in our study. However, the issue goes to the heart of where linguistic analysis stops and social cognition and affect begin. We suspect that although these domains may be separated analytically, they are in fact inextricably intertwined (see Van Berkum, 2015) - real language use is inevitably also social action, and language interpretation is therefore also deeply social and affective.

Finally, how "language-specific" are our findings on linguistically induced cognitive perspective-taking and other cognitive processes associated with linguistic discourse? We think the most sensible position here is to accept that most of the indirectness effects we report here will not be language specific. For one, cognitive perspective-taking is not limited to linguistic discourse, neither in pragmatic accounts of inferential communication (e.g. Levinson, 2006; Tomasello, 2008), nor in how the associated network can be made to light up in fMRI studies (e.g., see Mar, 2011, for a meta-analysis of verbal and non-verbal ToM studies). Furthermore, major nodes of the latter mentalizing network have also been associated with other functions (see, e.g., Binder and Desai, 2011; Cabeza et al., 2012; Humphreys and Lambon Ralph, 2014). Fronto-temporal areas that are more heavily taxed by the complexity inherent in face-saving indirect replies may involve working memory, episodic memory, and executive control over both (e.g., via selection or inhibition; see Fedorenko, 2014), again presumably generic processes, recruited in the service of language comprehension. And of course nobody would claim that saliencerelated affective processing is specific to language. Our prediction, therefore, is that a non-verbal design with face-saving indirect gestures should generate comparable results. On the whole, language processing seems to require a number of networks, 
including core networks for memory and unification, with the recruitment of additional networks that support the rich cognitive and affective infrastructure in which the language system is embedded (see Hagoort, 2005, 2013, 2014; Van Berkum, 2015, for perspective and details).

\section{Conclusion}

We have seen that the comprehension of face-saving indirect replies, an important device that communicators use to navigate the social world, selectively recruits virtually all of the brain areas in active addressees and active overhearers that we also saw recruited in a "passive" experimental design, with passive overhearers. This is quite compelling, as the replication was carried out with a different task, different stimuli and different participants, and with different 'faces' to be saved, for different reasons. Important core processes of understanding what the speaker is really saying thus appear to be stable across a variety of settings, i.e. can be observed both in a passive listening task that is representative of the majority of neurobiology of language experiments, and in a more natural action oriented overhearing task where the focus was on "doing things with language".

In line with pragmatic analysis (e.g., Grice, 1975; Clark, 1996), understanding language heavily relies on recognizing the intention of the communicative partner. One of the original contributions of this study was to move the focus from examining language-as-product to language-as-action - that is, the participants' goal was to do something with the information derived from direct and indirect utterances, not just simply listen to them. We showed that the basic infrastructure for cognitive perspectivetaking and for dealing with the complexity of an extended discourse does not significantly change in such an active paradigm. We also showed that for these cognitive operations, it does not matter whether the face-saving indirect replies are directed towards the participants themselves, or to a third person - presumably because the same inferential and representational work needs to be done in either situation. What does change with listener status is the activity in brain areas associated with emotional salience. This makes sense: whether somebody is navigating you or somebody else with evasive indirect language should matter somewhere, and affective responses to what a person is trying to achieve, i.e., his or her social move, is an obvious place to look.

\section{Acknowledgments}

We want to thank Laura Arendsen, Brenda Lelie, José Kivits and Marjolijn van Gelder for recording the questions and replies used in the Job interview, as well as Paul Gaalman for technical assistance with data acquisition. JB was partly supported by VEGA Grant 2/0154/13, JvB was supported by NWO Vici Grant \#277-89001.

\section{Appendix A.}

Example of one job interview. Direct question-reply pairs are in italics, indirect question-reply pairs are in bold. The rest are filler items. The interview is for the position of office manager. The interviews were conducted in Dutch.

1. Q: How good are your typing skills?

$\mathrm{R}$ : Quite normal, in my opinion. My previous employer was satisfied with me.
2. Q: Do you speak any foreign languages?

R: Uhm... I speak very good German but not any other languages. Well, I also speak some English but I am much better in passive English than in really... really using English.

3. Q: How are you going to improve your language skills?

$R$ : I am planning to follow an English course this summer.

4. Q: Do you have any experience with writing yearly reports? $\mathrm{R}$ : Hm, I don't really have any experience but I've read some on the internet. It does not look too difficult and I am a really good writer.

5. Q: Have you applied for any other positions before applying for this job?

$\mathrm{R}$ : Yes, I've applied in every bigger city in the country apart from the one where I live.

6. $\mathbf{Q}$ : You have a gap of several years on your $\mathrm{CV}$ since your last job. Is this the first job interview you have been invited to? R: Finding a job in my area is extremely difficult.

7. Q: Do you have experience with business correspondence in English?

$\mathrm{R}$ : I remember that we had to write business letters in school, but not too often.

8. Q: Why do you fit into this line of work - personality-wise? $R$ : I have all the personal qualities to work with finances.

9. Q: I can see that your previous job lasted less than three months. Did you resign voluntarily?

R: I came there in the middle of a restructuring process and the newcomers had to leave as the first ones.

10. Q: Do you have any experience with electronic scheduling programs?

R: Eeh, yes, I have tried several different types and I can work with them very well.

11. Q: Which of the skills you listed on your CV have you not yet had the chance to apply into practice?

$R$ : I have never needed to work with Powerpoint.

\section{Appendix B. Supplementary materials}

Supplementary data associated with this article can be found in the online version at http://dx.doi.org/10.1016/j.neuropsychologia. 2015.03.030.

\section{References}

Bambini, V., Bara, B.G., 2012. Neuropragmatics In: Östman, J.-O., Verschueren, J. (Eds.), Handbook of Pragmatics. John Benjamins, Amsterdam, Philadelphia.

Barrett, L.F., Satpute, A.B., 2013. Large-scale brain networks in affective and social neuroscience: towards an integrative functional architecture of the brain. Curr. Opin. Neurobiol. 23 (3), 361-372.

Bašnáková, J., Weber, K., Petersson, K.M., van Berkum, J., Hagoort, P., 2014. Beyond the language given: the neural correlates of inferring speaker meaning. Cereb. Cortex 24 (10), 2572-2578.

Bernhardt, B.C., Singer, T., 2012. The neural basis of empathy. Annu. Rev. Neurosci. 35 (1), $1-23$.

Binder, J.R., Desai, R.H., 2011. The neurobiology of semantic memory. Trends Cogn. Sci. 15, 527-536.

Boersma, P., Weenink, D., 2009. Praat: Doing Phonetics by Computer. Computer Program Version 4322. 〈www.praat.org $\rangle$.

Bohrn, I.C., Altmann, U., Jacobs, A.M., 2012. Looking at the brains behind figurative language-a quantitative meta-analysis of neuroimaging studies on metaphor, idiom, and irony processing. Neuropsychologia 50 (11), 2669-2683.

Bottini, G., Corcoran, R., Sterzi, R., Paulesu, E., Schenone, P., Scarpa, P., Frith, D., 1994. The role of the right hemisphere in the interpretation of figurative aspects of language: a positron emission tomography activation study. Brain 117 (6), 1241-1253.

Boyd, B., 2009. On the Origin of Stories: Evolution, Cognition, and Fiction. The Belknap Press of Harvard University Press, Cambridge, MA.

Brett, M., Anton, J.-L.L., Valabregue, R., Poline, J.-B., 2002. Region of interest analysis using an SPM toolbox [abstract]. Presented at the 8th International Conference on Functional Mapping of the Human Brain, June 2-6, 2002, Sendai, Japan. In: Neurolmage 
(vol. 16, p. abstract 497)

Brown, P., Levinson, S.C., 1987. Politeness: Some Universals in Language Usage. Cambridge University Press, Cambridge.

Buckner, R.L., Andrews-Hanna, J.R., Schacter, D.L., 2008. The brain's default network: anatomy, function, and relevance to disease. Ann. N. Y. Acad. Sci. 1124, 1-38.

Busselle, R., Bilandzic, H., 2008. Fictionality and perceived realism in experiencing stories: a model of narrative comprehension and engagement. Commun. Theory 18 (2) $255-280$

Cabeza, R., Ciaramelli, E., Moscovitch, M., 2012. Cognitive contributions of the ventral parietal cortex: an integrative theoretical account. Trends Cogn. Sci. 16, 338-352.

Clark, H.H., 1996. Using Language. Cambridge University Press, Cambridge.

Clark, H.H., 2006. Social actions, social commitments In: Stephen, C., Levinson, Enfield, N J. (Eds.), Roots of Human Sociality: Culture, Cognition, and Human Interaction. Berg Press, Oxford, pp. 126-150.

Cohen, J., 2001. Defining Identification: a theoretical look at the identification of audiences with media characters. Mass Commun. Soc. 4 (3), 245-264.

Decety, J., Lamm, C., 2006. Human empathy through the lens of social neuroscience. Sci. World J. 6, 1146-1163.

Fan, Y., Duncan, N.W., de Greck, M., Northoff, G., 2011. Is there a core neural network in empathy? An fMRI based quantitative meta-analysis. Neurosci. Biobehav. Rev. 35 (3), 903-911.

Fedorenko, E., 2014. The role of domain-general cognitive control in language comprehension. Front. Psychol. 5, 335.

Ferstl, E.C., von Cramon, D.Y., 2002. What does the frontomedian cortex contribute to language processing: coherence or theory of mind? NeuroImage 1612, 1599-1612.

Ferstl, E., Neumann, J., Bogler, C., von Cramon, D.Y., 2008. The extended language network: a metaanalysis of neuroimaging studies on text comprehension. Hum. Brain Mapp. 29 (5), 581-593.

Goffman, E., 1959. The Presentation of Self in Everyday Life. Doubleday Anchor, New York.

Gottschall, J., 2012. The storytelling animal: How stories make us human. Houghton Mifflin Harcourt, New York.

Green, M.C., Brock, T.C., 2000. The role of transportation in the persuasiveness of public narratives. J. Personal. Soc. Psychol. 79 (5), 701-721.

Grice, H.P., 1975. Logic and conversation In: Cole, P., Morgan, J.L. (Eds.), Syntax and Semantics, vol. 3. Academic Press, New York, pp. 41-58.

Hagoort, P., 2005. On broca, brain, and binding: a new framework. Trends Cogn Sci 9, 416-423.

Hagoort, P., 2013. MUC (Memory, Unification, Control) and beyond. Front. Psychol. 4, 416.

Hagoort, P., Baggio, G., Willems, R., 2009. Semantic unification In: Gazzaniga, M.S. (Ed.), The Cognitive Neurosciences. MIT Press, Cambridge, MA, pp. 819-836.

Hagoort, P., Hald, L., Bastiaansen, M.C.M., Petersson, K.-M., 2004. Integration of word meaning and world knowledge in language comprehension. Science 304 (5669), $438-441$.

Hagoort, P., Levinson, S.C., 2014. Neuropramatics In: Gazzaniga, M.S., Mangun, G.R. (Eds.), The Cognitive Neurosciences. MIT Press, Cambridge, MA, pp. 667-674.

Hervé, P.-Y., Razafimandimby, A., Jobard, G., Tzourio-Mazoyer, N., 2013. A shared neura substrate for mentalizing and the affective component of sentence comprehension. PloS One 8 (1), e54400.

Hoeks, J.C., Brouwer, H., 2014. Electrophysiological research on conversation and discourse In: Holtgraves, T.M.H. (Ed.), The Oxford Handbook of Language and Social Psychology. Oxford University Press, New York, pp. 365-386.

Holtgraves, T.M., 2002. Language as Social Action: Social Psychology and Language Use Erlbaum, Mahwah, NJ.

Humphreys, G.F., Lambon Ralph, M.A., 2014. Fusion and fission of cognitive functions in the human parietal cortex. Cereb. Cortex, http://dx.doi.org/10.1093/cercor/bhu198.

Jang, G., Yoon, S.A., Lee, S.E., Park, H., Kim, J., Ko, J.H., Park, H.J., 2013. Everyday conversation requires cognitive inference: neural bases of comprehending implicated meanings in conversations. NeuroImage $81,61-72$.

Kircher, T.T.J., Brammer, M., Andreu, N.T., Williams, S.C.R., McGuire, P.K., 2001. Engagement of right temporal cortex during processing of linguistic context. Neuropsychologia 39 (8), 798-809.

Kuperberg, G.R., Lakshmanan, B.M., Caplan, D.N., Holcomb, P.J., 2006. Making sense of discourse: an fMRI study of causal inferencing across sentences. Neurolmage 33 (1) 343-361.

Landauer, T., Foltz, P., Laham, D., 1998. An introduction to latent semantic analysis. Discourse Process. 25 (2), 259-284.

Landauer, T.K., Dumais, S.T., 1997. A solution to Plato's problem: the latent semantic analysis theory of acquisition, induction, and representation of knowledge. Psychol. Rev. 104 (2), 211-240.

Lauro, L.J.R., Tettamanti, M., Cappa, S.F., Papagno, C., 2008. Idiom comprehension: prefrontal task? Cereb. Cortex 18 (1), 162-170.

Lee, J.J., Pinker, S., 2010. Rationales for indirect speech: the theory of the strategic speaker. Psychol. Rev. 117 (3), 785-807.

Levinson, S.C., 2006. On the human "interaction engine." In: Enfield, N.J., Levinson, S.C. (Eds.), Roots of Human Sociality: Culture, Cognition and Interaction. Berg, Oxford, pp. 39-69.

Li, S., Jiang, X., Yu, H., Zhou, X., 2014. Cognitive empathy modulates the processing of pragmatic constraints during sentence comprehension. Soc. Cogn. Affect. Neurosci. 9 (8), 1166-1174.

Mar, R.A., Oatley, K., 2008. The function of fiction is the abstraction and simulation of social experience. Perspect. Psychol. Sci. 3 (3), 173-192.

Mars, R.B., Neubert, F.-X., Noonan, M.P., Sallet, J., Toni, I., Rushworth, M.F.S., 2012. On the relationship between the "default mode network" and the "social brain.". Front. Hum. Neurosci. 6, 189.

Mason, R.A., Just, M.A., 2011. Differentiable cortical networks for inferences concerning people's intentions versus physical causality. Hum. Brain Mapp. 32 (2), 313-329.

Nieuwland, M.S., Petersson, K.M., Van Berkum, J.J.A., 2007. On sense and reference: Examining the functional neuroanatomy of referential processing. Neurolmage 37 (3), 993-1004.

Nieuwland, M.S., Van Berkum, J.J.A., 2008. The neurocognition of referential ambiguity in language comprehension. Linguist. Lang. Compass 2 (4), 603-630.

Noordzij, M.L., Newman-Norlund, S.E., de Ruiter, J.P., Hagoort, P., Levinson, S.C., Toni, I., 2009. Brain mechanisms underlying human communication. Front. Hum. Neurosci. $3,14$.

Pinker, S., Nowak, M.A., Lee, J.J., 2008. The logic of indirect speech. Proc. Natl. Acad. Sci. U. S. A. 105 (3), 833-838.

Poser, B.A., Versluis, M.J., Hoogduin, J.M., Norris, D.G., 2006. BOLD contrast sensitivity enhancement and artifact reduction with multiecho EPI: parallel-acquired inhomogeneity-desensitized fMRI. Magn. Reson. Med. 55 (6), 1227-1235.

Proverbio, A.M., Crotti, N., Zani, A., Adorni, R., 2009. The role of left and right hemispheres in the comprehension of idiomatic language: an electrical neuroimaging study. BMC Neurosci. 10 (1), 116.

Rapp, A.M., Mutschler, D.E., Erb, M., 2012. Where in the brain is nonliteral language? A coordinate-based meta-analysis of functional magnetic resonance imaging studies. NeuroImage 63 (1), 600-610.

Schilbach, L., Eickhoff, S.B., Rotarska-Jagiela, A., Fink, G.R., Vogeley, K., 2008. Minds at rest? Social cognition as the default mode of cognizing and its putative relationship to the "default system" of the brain. Conscious. Cogn. 17 (2), 457-467.

Schober, M.F., Clark, H.H., 1989. Understanding by addressees and overhearers. Cogn. Psychol. 21 (2), 211-232.

Schurz, M., Aichhorn, M., Martin, A., Perner, J., 2013. Common brain areas engaged in false belief reasoning and visual perspective taking: a meta-analysis of functional brain imaging studies. Front. Hum. Neurosci. 7, 712.

Slater, M.D., Rouner, D., 2002. Entertainment-education and elaboration likelihood: understanding the processing of narrative persuasion. Commun. Theory 12 (2), $173-191$.

Spotorno, N., Koun, E., Prado, J., Van Der Henst, J.B., Noveck, I.A., 2012. Neural evidence that utterance-processing entails mentalizing: the case of irony. Neurolmage 63 (1), 25-39.

St George, M., Kutas, M., Martinez, A., Sereno, M.I., 1999. Semantic integration in reading: engagement of the right hemisphere during discourse processing. Brain 122 (7) $1317-1325$.

Stolk, A., Verhagen, L., Schoffelen, J.-M., Oostenveld, R., Blokpoel, M., Hagoort, P., Toni, I., 2013. Neural mechanisms of communicative innovation. Proc. Natl. Acad. Sci. U. S. A. 110 (36), 14574-14579.

Taylor, K.S., Seminowicz, D.A., Davis, K.D., 2009. Two systems of resting state connectivity between the insula and cingulate cortex. Hum. Brain Mapp. 30 (9), 2731-2745.

Tomasello, M., 2008. Origins of Human Communication. p. 379.

Tylén, K., Wallentin, M., Roepstorff, A., 2009. Say it with flowers! An fMRI study of object mediated communication. Brain Lang. 108 (3), 159-166.

Van Ackeren, M.J., Casasanto, D., Bekkering, H., Hagoort, P., Rueschemeyer, S.-A., 2012. Pragmatics in action: indirect requests engage theory of mind areas and the cortical motor network. J. Cogn. Neurosci. 24 (11), 2237-2247.

Van Berkum, J.J.A., 2009. The neuropragmatics of "simple" utterance comprehension: an ERP review In: Sauerland, U., Yatsushiro, K. (Eds.), Semantics and Pragmatics: From Experiment to Theory. Palgrave Macmillan, Basingstoke, pp. 276-316.

Van Berkum, J.J.A., 2010. The brain is a prediction machine that cares about good and bad -any implications for neuropragmatics. Ital. J. Linguist. 22 (1), 181-208.

Van Berkum, J.J.A., 2015. Language comprehension and emotion: where are the interfaces, and who cares? To appear In: Miozzo, M., de Zubicaray, G., Schiller, N.O. (Eds.) Oxford Handbook of Neurolinguistics. OUP, Oxford.

Van Berkum, J.J.A., Brown, C.M., Hagoort, P., 1999. Early referential context effects in sentence processing: evidence from event-related brain potentials. J. Mem. Lang. 41 (2), 147-182

Van Overwalle, F., Baetens, K., 2009. Understanding others' actions and goals by mirror and mentalizing systems: a meta-analysis. Neurolmage 48 (3), 564-584.

Visser, M., Lambon Ralph, M.A., 2011. Differential contributions of bilateral ventral anterior temporal lobe and left anterior superior temporal gyrus to semantic processes. J. Cogn. Neurosci. 23 (10), 3121-3131.

Vuilleumier, P., 2005. How brains beware: neural mechanisms of emotional attention. Trends Cogn. Sci. 9 (12), 585-594.

Wang, A.T., Lee, S.S., Sigman, M., Dapretto, M., 2006. Neural basis of irony comprehension in children with autism: the role of prosody and context. Brain 129 (4), 932-943.

Wong, C., Gallate, J., 2012. The function of the anterior temporal lobe: a review of the empirical evidence. Brain Res. 1449, 94-116.

Zempleni, M.Z., Haverkort, M., Renken, R., A. Stowe, L., 2007. Evidence for bilateral involvement in idiom comprehension: an fMRI study. NeuroImage 34 (3), 1280-1291.

Zwaan, Ra, Radvansky, Ga, 1998. Situation models in language comprehension and memory. Psychol. Bull. 123 (2), 162-185. 